Article

\title{
Oxidative desulfurization of diesel fuel with caprolactam-based acidic deep eutectic solvents: Tailoring the reactivity of DESs by adjusting the composition
}

\author{
Lingwan Hao, Ting Su, Dongmei Hao, Changliang Deng, Wanzhong Ren, Hongying Lü* \\ Green Chemistry Centre, College of Chemistry and Chemical Engineering, Yantai University, Yantai 264005, Shandong, China
}

\section{A R T I C L E I N F O}

\section{Article history:}

Received 16 March 2018

Accepted 24 April 2018

Published 5 September 2018

\section{Keywords:}

Acidic deep eutectic solvents

Diesel

Dibenzothiophene

Hydrogen bond

Oxidative desulfurization

\begin{abstract}
A B S T R A C T
Despite the significance of hydrogen bonding in deep eutectic solvents (DESs) for desulfurization processes, little is understood about the relationship between the DES composition, hydrogen-bonding strength, and oxidative desulfurization activity. In this study, a new family of caprolactam-based acidic DESs was prepared with different molar ratios of caprolactam and oxalic acid. The prepared DESs were characterized by differential scanning calorimetry, Fourier transform infrared spectroscopy, ${ }^{1} \mathrm{H}$ nuclear magnetic resonance, and thermogravimetric analyses. These DESs were employed for oxidative desulfurization reactions and the desulfurization efficiency was found to vary regularly with the DES composition. The factors influencing the removal of dibenzothiophene were systematically investigated and the desulfurization efficiency of the caprolactam-based acidic DESs reached as high as $98 \%$ under optimal conditions. The removal of different sulfur compounds followed the order: dibenzothiophene > 4,6-dimethyldibenzothiophene > benzothiophene. The combined experimental data and characterization results revealed that the oxidative desulfurization efficiency of the system was influenced by the hydrogen bonding interactions with the DES, which can be optimized by adjusting the DES composition. These findings regarding hydrogen bonding in DESs provide new insight for better understanding of the mechanism of diesel deep desulfurization processes.
\end{abstract}

(C) 2018, Dalian Institute of Chemical Physics, Chinese Academy of Sciences. Published by Elsevier B.V. All rights reserved.

\section{Introduction}

The sulfur oxides in automobile exhaust have become a key aspect of the problem of acid rain and particulate matter (PM) 2.5. As a result, governments around the world regulate the composition and quality of transportation fuels to reduce such automobile exhaust emissions. Since 2006, the U.S. environmental legislation has limited the sulfur content in diesel to 15 $\mu \mathrm{g} \mathrm{g}^{-1}$ [1-3]. Hydrodesulfurization (HDS) processes have been commercially applied to produce diesel fuel as a mature technology carried out under high hydrogen pressures and tem- peratures. However, the reduction of thiophenic compounds and their derivatives is difficult [4]. In addition, the harsh reaction conditions and high costs hamper further developments in desulfurization systems. Therefore, alternative processes for the deep desulfurization of fuels have become a hot topic from the perspective of high energy-efficiency applications. Among them, oxidative desulfurization (ODS) has been recently attracting a lot of attention for its mild operating conditions in the absence of hydrogen [5-15]. Nevertheless, the main limitation in the industrial application of ODS is the use of large amounts of volatile and flammable organic extractants, which

* Corresponding author. Tel/Fax: +86-535-6902063; E-mail: hylv@ytu.edu.cn, hylvytu@163.com This work was supported by the National Natural Science Foundation of China (21676230, 21373177).

DOI: 10.1016/S1872-2067(18)63091-8| http://www.sciencedirect.com/science/journal/18722067 | Chin. J. Catal., Vol. 39 , No. 9, September 2018 
result in further environmental pollution and safety issues. To solve these problems, a system combining ionic liquid (IL) extraction with catalytic oxidative desulfurization was successfully introduced, which could avoid the above environmental safety issues [16-21]. The industrial scale application of IL technologies still possess some challenges in terms of purification difficulties, high cost, low biodegradability, and hazardous toxicity [22-24]. Therefore, the exploration of new green solvents for desulfurization processes at large scale is urgent.

Deep eutectic solvents (DESs), a new class of versatile alternatives to ILs, have shown tremendous promise [25-28]. DESs refer to eutectic mixtures constituted by two or three cheap environmental ingredients associated via hydrogen bonding. They not only display the advantages of traditional ILs, but also surmount some of their deficiencies [26]. DESs exhibit extraordinary physical and chemical properties, such as viscosity, polarity, surface tension, conductivity, thermal stability, negligible vapor pressure, and being non-flammable. Moreover, these eutectic mixtures are nontoxic, biodegradable, inexpensive, and easy to prepare from natural and ready-made raw materials. As a new type of green solvents, research on DESs has intensified in the last decade, ever since their potential in new chemical technologies was realized [29,30]. Among the existing literatures, the ODS of fuels using DESs has attracted wide attention [31-38]. Li's group synthesized a series of acidic DESs for deep oxidation/extraction desulfurization of model fuels and the desulfurization efficiency of such DESs reached up to $99.99 \%$ [31]. Zhu et al. [32] developed a liquid-liquid extraction and photochemical oxidative desulfurization system exhibiting a dibenzothiophene (DBT) removal of up to $98.6 \%$ under UV light irradiation. Li's group utilized the DES choline chloride/2 polyethylene glycol for desulfurization and the removal of DBT reached up to $99.1 \%$ [33]. Mao et al. [34] reported a class of propionic acid-based DESs $\left(\mathrm{C}_{3} \mathrm{H}_{6} \mathrm{O}_{2} / X \mathrm{ZnCl}_{2}\right.$, $X=0.1-0.6$ ) and the desulfurization of DBT reached $99.42 \%$. In a previous work, we found that the aromaticity of sulfur compounds was weakened by strong hydrogen bonding interactions in DESs, leading to easier oxidation to the corresponding sulfones by peracids [35]. Despite the significance of hydrogen bonding in DESs in desulfurization reactions, little understanding exists on the relationship between the DES composition, hydrogen-bonding strength, and oxidative desulfurization activity. As is well known, compared to the prediction of hydrogen-bonding strength (hydrogen bond puzzle) [39], establishing its relationship with the oxidation desulfurization efficiency has proven to be more difficult. Therefore, the relevant works in the literature are just preliminary investigations and further insight is urgently required.

In this paper, a series of caprolactam-based acidic DESs derived from common starting materials was prepared and employed as extractants and catalysts for the ODS of diesel. When employed in ODS reactions, the desulfurization efficiency was found to vary regularly with the DES composition. Under optimal conditions, the desulfurization efficiency of the caprolactam-based acidic DES reached 98\%. The effect of the DES composition, reaction temperature, oxidant dosage, and different sulfur compounds on the desulfurization reaction was investi- gated. Since hydrogen bonding in caprolactam-based acidic DESs plays a vital role in ODS reactions, this work focused on the relationship between the ODS efficiency and hydrogen-bonding strength. Our findings on the effect of hydrogen bonding in DESs provide new insight into the mechanism of diesel deep desulfurization. The mechanism of this ODS system is also discussed based on a dual activation concept.

\section{Experimental}

\subsection{Materials}

Caprolactam (CPL), DBT, and benzothiophene (BT) were purchased from Macklin Reagent (Shanghai, China). Oxalic acid dihydrate and 4,6-dimethyldibenzothiophene (4,6-DMDBT) were purchased from Sinopharm Chemical Reagent (Shanghai, China). All the chemicals were analytical reagents dried under vacuum before use.

\subsection{DES preparation}

CPL was chosen as the HBA and oxalic acid (OXA) was chosen as the HBD. The synthesis process was performed in a round-bottomed flask. The DESs were prepared by stirring the two ingredients at given molar ratios at $80{ }^{\circ} \mathrm{C}$ until a homogeneous liquid was obtained [28]. This approach provided DESs with $100 \%$ atom economy and no by-product generation.

\subsection{Characterization of DESs}

The melting points $\left(T_{\mathrm{m}}\right)$ and glass transition temperatures $\left(T_{\mathrm{g}}\right)$ of the DESs were determined by differential scanning calorimetry (DSC $204 \mathrm{HP}$ ) from the second heating cycle, after initially heating the sample up to $100^{\circ} \mathrm{C}$ and then cooling it to -70 ${ }^{\circ} \mathrm{C}$. The $T_{\mathrm{m}}$ values were obtained by heating at a rate of $10{ }^{\circ} \mathrm{C}$ $\mathrm{min}^{-1}$ under nitrogen atmosphere. Fourier transform infrared (FT-IR) spectroscopy measurements were carried out on a Nicolet 470 FT-IR spectrometer using the $\mathrm{KBr}$ pellet technique. ${ }^{1} \mathrm{H}$ nuclear magnetic resonance $\left({ }^{1} \mathrm{H} \mathrm{NMR}\right)$ spectra were recorded on a Bruker DRX $400 \mathrm{MHz}$ spectrometer at room temperature (400 MHz) and internally referenced to the tetramethylsilane signal in $\mathrm{CDCl}_{3}$. Thermo-gravimetric analyses (TGA) were performed on a NETZSCH STA409PC thermal analyzer at a heating rate of $10{ }^{\circ} \mathrm{C} \mathrm{min}-1$ from 25 to $300{ }^{\circ} \mathrm{C}$ under nitrogen atmosphere.

\subsection{Oxidation and desulfurization of model diesel}

An oil bath was heated to the chosen temperature. The concentration of sulfur was $500 \mu \mathrm{g} \mathrm{g}-1$ by dissolving the corresponding sulfur compound in $n$-octane. Tetradecane was chosen as the internal standard in such model diesel. The ODS system consisted of $2 \mathrm{~mL}$ DESs, $10 \mathrm{~mL}$ model diesel, and $0.09 \mathrm{~mL}$ of $30 \mathrm{wt} \% \mathrm{H}_{2} \mathrm{O}_{2}$. The mixture was then stirred constantly for 3 h. Model diesel aliquots (top phase) were periodically withdrawn for analysis. 


\subsection{Analysis of model diesel samples}

The samples were analyzed by gas chromatography with flame ionization detection (GC-FID) (FuLi 9750, HP-5 column, $30 \mathrm{~m}$ long $\times 0.32 \mathrm{~mm}$ inner diameter $\times 0.25 \mu \mathrm{m}$ film thickness). The analysis conditions were as follows: injector port temperature, $250{ }^{\circ} \mathrm{C}$; detector temperature, $300{ }^{\circ} \mathrm{C}$; oven temperature starting at $100{ }^{\circ} \mathrm{C}$ and rising to $200{ }^{\circ} \mathrm{C}$ at $15^{\circ} \mathrm{C} \mathrm{min}-1$ for DBT and BT, and rising to $250{ }^{\circ} \mathrm{C}$ at $25^{\circ} \mathrm{C} \mathrm{min}-1$ for 4,6-DMDBT. The results were also confirmed by microcoulometry [40]. The sulfur removal on the basis of DBT both from extraction and oxidation was calculated as indicated in equation (1):

Sulfur removal $(\%)=1-C_{\mathrm{DBT}}$ after reaction $/ C_{\mathrm{DBT}}$ in fresh model oil $(1)$ where $C_{\mathrm{DBT}}$ after reaction is the concentration of DBT after the desulfurization reaction and $C_{\text {fresh model diesel }}$ is the concentration of DBT in the fresh model oil.

\section{Results and discussion}

\subsection{Characterization of DESs}

To design a novel catalytic DES system for deep oxidative desulfurization, OXA was selected as the HBD and CPL as the HBA, from which a series of caprolactam-based acidic DESs with different molar ratios (denoted as the CPLO molar ratio) were prepared. A DSC analysis was carried out in order to determine the phase transition temperature of such caprolactam-based acidic DESs. All the DESs present a $T_{\mathrm{g}}$ in the range from -40 to $-50{ }^{\circ} \mathrm{C}$ (Fig. 1). With the increasing temperature, the DSC curve of the CPLO 1:2 sample exhibits a clear peak for the $T_{\mathrm{m}}\left(40.5^{\circ} \mathrm{C}\right)$, whose cold crystallization can be attributed to a subcooling phenomenon quite common in the thermal behavior of many liquids. Additionally, the three DSC curves for the CPLO 1:1, CPLO 2:1, and CPLO 3:1 DESs only display a glass transition peak at $-42.6,-44.2$ and $-47.2{ }^{\circ} \mathrm{C}$, respectively, without clear melting or freezing peaks, indicating that these eutectic mixtures may present a weak tendency toward crystallization [41]. The variations in $T_{\mathrm{g}}$ and $T_{\mathrm{m}}$ may be related to different hydrogen bonding in the DESs as a result of the varying molar ratios of the HBA and HBD $[42,43]$.

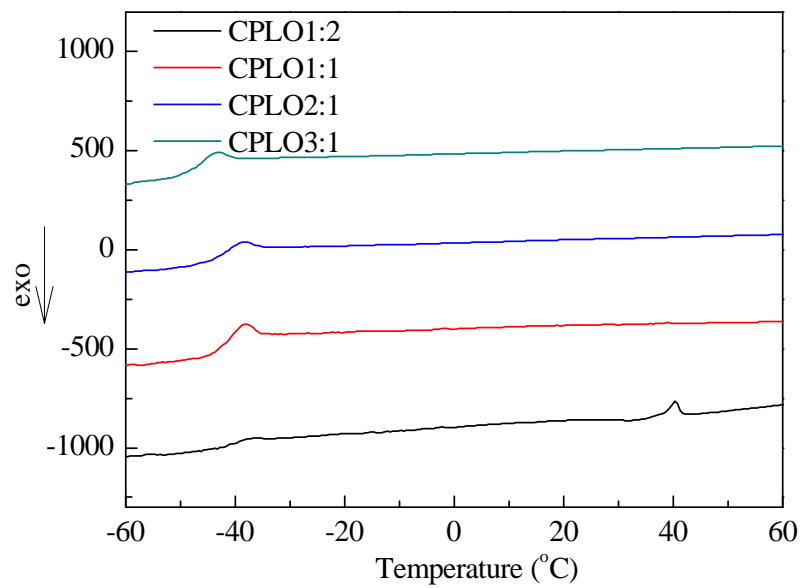

Fig. 1. DSC curves for the CPL/OXA mixtures at different molar ratios.
In order to study the composition of such caprolactam-based DESs, the FT-IR spectra of OXA, CPL, and different DESs (CPLO 1:2, CPLO 1:1, CPLO 2:1, and CPLO 3:1) were recorded, as shown in Fig. 2. The strong absorption band at 3416.5 $\mathrm{cm}^{-1}$ is attributed to the $\mathrm{OH}$ group of the carboxylic acid moieties. Compared to that in the OXA spectrum, the $\mathrm{OH}$ band of the caprolactam-based DESs is broader and weaker with the increasing molar ratio. These results further indicate the generation of stable hydrogen bonding between CPL and OXA $[33,44]$. Moreover, it can even be suggested that the hydrogen-bond strength is related to the DES composition.

The ${ }^{1} \mathrm{H}$ NMR spectra of the caprolactam-based acidic DESs at different CPL/OXA molar ratios were recorded to further determine the nature of the prepared DESs (Fig. 3). The resonance for the carboxylic acid proton in these eutectic mixtures shifts downfield with the increasing CPL molar fraction [45, 46], reaching the lowest chemical shift of $13.56 \mathrm{ppm}$ for the CPLO 3:1 sample. This result suggests that the strongest hydrogen-bonding was obtained at such molar ratio (3:1), also implying that the hydrogen-bond strength between the HBD and HBA is correlated with the DES composition. In addition, the ${ }^{1} \mathrm{H}$ chemical shift for the $\mathrm{N}-\mathrm{H}$ proton of CPL appears at 6.25 ppm, shifting downfield with the increasing CPL/OXA molar ratio in the DESs. These results confirm again that the hydrogen-bonding strength varies with the DES composition.

To further understand the nature of the hydrogen bonding between CPL and OXA, the thermal behavior of the DESs was studied by TGA. A comparison of the TGA curves of the caprolactam-based acidic DESs is shown in Fig. 4(a). It is observed that the CPLO 3:1 sample exhibits high thermal stability with a weight loss of $76 \%$ at $225{ }^{\circ} \mathrm{C}$, remarkably lower than these of the other three DESs. This fact confirms that the composition of the DESs plays an important role in their thermal stability. In addition, it can be seen from Fig. 4(b) that the CPLO 3:1 mixture successfully delayed the decomposition of its original components (CPL and OXA). At $225^{\circ} \mathrm{C}, 24 \%$ of the CPLO 3:1 DES still remained, while both pure CPL and OXA were already completely decomposed. Thus, from these results, it could be inferred that caprolactam-based acidic DESs are successfully

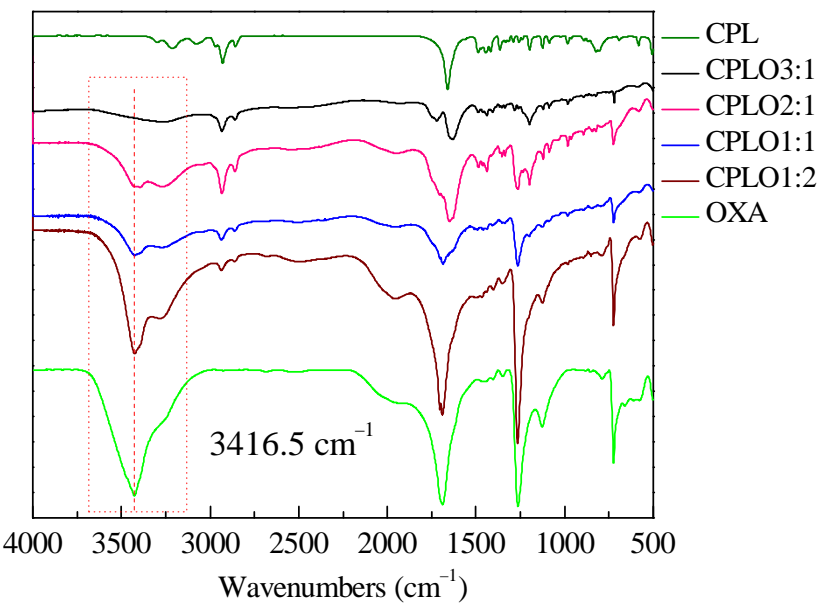

Fig. 2. FT-IR spectra of CPL, OXA, and the caprolactam-based acidic DESs. 


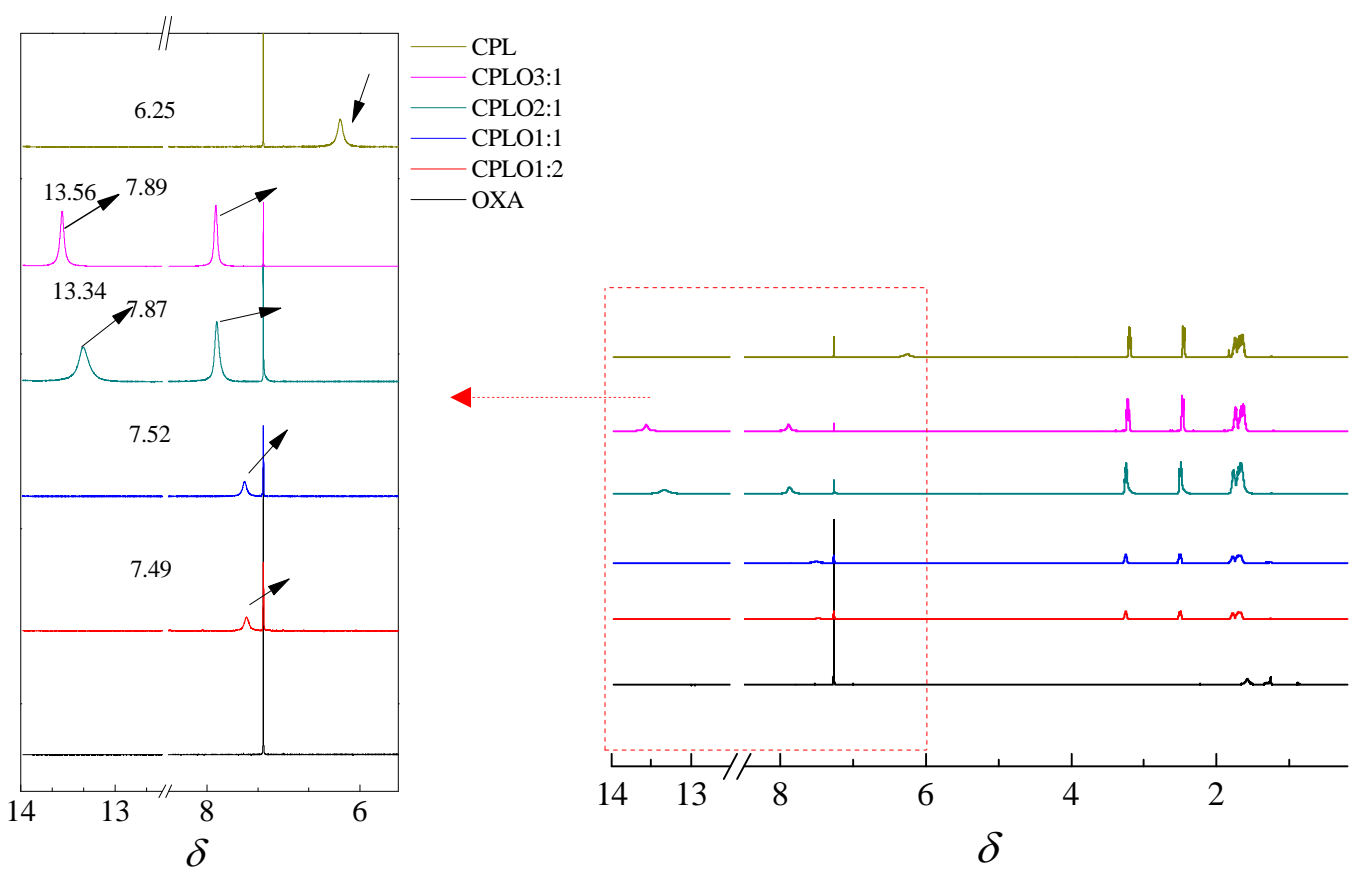

Fig. 3. ${ }^{1} \mathrm{H}$ NMR spectra of the caprolactam-based acidic DESs at different molar ratios.
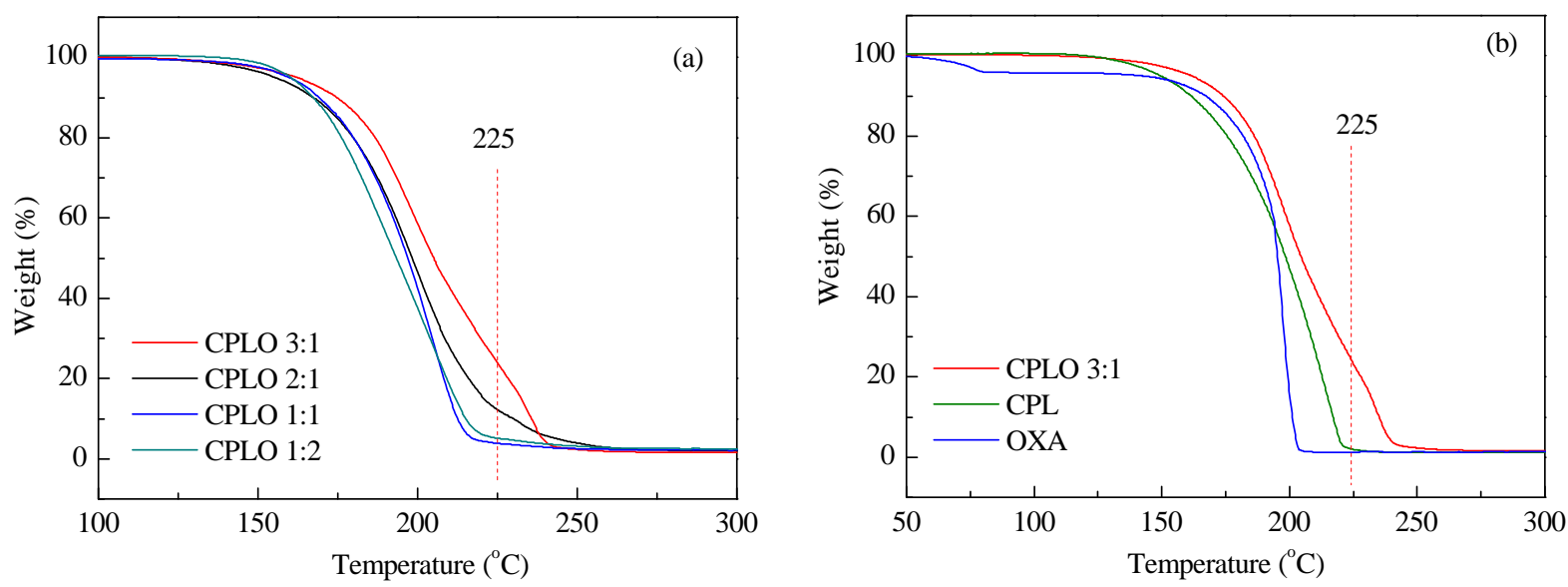

Fig. 4. TGA curves of the caprolactam-based acidic DESs (a) and the CPLO 3:1 DES, CPL, and OXA (b).

formed through hydrogen bonding between the CPL and OXA components and that the CPLO 3:1 DES presents the strongest hydrogen bonds of all the prepared DESs [47]. Furthermore, taking into account the above characterization, it was further demonstrated that the hydrogen bonding in DESs could be adjusted by altering the molar ratio of HBA and HBD.

\subsection{Effect of different desulfurization systems on DBT removal}

The desulfurization efficiency via extraction combined with catalytic oxidation of the different caprolactam-based acidic mixtures is shown in Table 1. With the increasing CPL molar ratio, the extraction efficiency gradually increases, probably owing to the 'like dissolves like' property of CPL and DBT as both contain a cyclic structure. It can be seen that DBT was more difficult to remove in the absence of $\mathrm{H}_{2} \mathrm{O}_{2}$. Furthermore, the removal of DBT by extraction coupled with catalytic oxida- tion increased with the CPL molar fraction. It is interesting to note that the sample with CPL/OXA molar ratio of 3:1 displays the highest desulfurizing ability, corresponding to the lowest $T_{\mathrm{g}}$

Table 1

Effect of different desulfurization systems on DBT removal.

\begin{tabular}{lccc}
\hline \multirow{2}{*}{ Entry } & \multirow{2}{*}{ Name } & \multicolumn{2}{c}{ Sulfur removal (\%) } \\
\cline { 3 - 4 } & & EDS $^{\text {a }}$ & ECODS $^{\text {b }}$ \\
\hline 2 & CPLO 1:2 & 8.0 & 54.0 \\
3 & CPLO 1:1 & 11.9 & 62.6 \\
4 & CPLO 2:1 & 20.8 & 75.4 \\
5 & CPLO 3:1 & 25.4 & 98.4 \\
\hline
\end{tabular}

Reaction conditions: a $V$ (caprolactam-based acidic mixture) $=2 \mathrm{~mL}$, $V($ model diesel $)=10 \mathrm{~mL}, t=30 \mathrm{~min}, T=60^{\circ} \mathrm{C}$, DBT (S: $\left.500 \mu \mathrm{g} \mathrm{g}^{-1}\right)$ in $n$-octane; b $V$ (caprolactam-based acidic mixture) $=2 \mathrm{~mL}, V($ model diesel $=10 \mathrm{~mL}, t=3 \mathrm{~h}, n\left(\mathrm{H}_{2} \mathrm{O}_{2}\right) / n(\mathrm{DBT})=5, T=60^{\circ} \mathrm{C}$, DBT (S: $\left.500 \mu \mathrm{g} \mathrm{g}^{-1}\right)$ in $n$-octane. 
value $\left(-47.2{ }^{\circ} \mathrm{C}\right)$ of the three caprolactam-based acidic DESs lacking clear melting or freezing peaks. This may suggest that there is a correlation between the composition and desulfurization activity of such caprolactam-based acidic DESs. The composition of the DESs plays a vital role not only on their physical performance, but also on their chemical properties, viz., their desulfurization activity $[28,35]$.

\subsection{Effect of reaction parameters on DBT removal}

To further analyze the performance of the CPLO 3:1 DES desulfurization system, the effects of the reaction temperature, oxidant dosage $(0 / \mathrm{S})$, and volume ratio of DES to model diesel $\left(V_{\mathrm{DES}} / V_{\text {model diesel }}\right)$ were evaluated. The DBT removal at 50,60 , 70 , and $80{ }^{\circ} \mathrm{C}$ is shown in Fig. 5, where the removal of DBT is seen to increase with the reaction temperature. The CPLO 3:1 DES system reached 98\% DBT removal in $3 \mathrm{~h}$ at all temperatures except at $50{ }^{\circ} \mathrm{C}$, probably due to the limited number of active centers at such low temperature [48]. As a result, it was obvious to select $60^{\circ} \mathrm{C}$ as the optimum reaction temperature.

To gain insight into the effect of the oxidant dosage on the desulfurization reaction, the removal of DBT with the CPLO 3:1 DES at different $\mathrm{O} / \mathrm{S}$ molar ratios $(\mathrm{O} / \mathrm{S}=3,4,5$, and 6$)$ was carried out at $60^{\circ} \mathrm{C}$ (Fig. 6). At $\mathrm{O} / \mathrm{S}$ ratios of 5 and 6 , the removal of DBT reached $98 \%$ in $3 \mathrm{~h}$. From the efficiency and economic points of view, an $0 / \mathrm{S}$ molar ratio of 5 was selected as the optimum oxidant dosage.

So as to explore the effect of the DES-to-oil volume ratio, experiments on the removal of DBT were carried out at various DES/model diesel ratios (Fig. 7). The larger the DES/model diesel ratio, the more efficient the ODS of DBT. The DBT removal was enhanced from $59 \%$ to $91 \%$ after $3 \mathrm{~h}$ with the increasing volume ratio from $1 / 20$ to $1 / 10$; however, the desulfurization performance was the highest at a DES/oil volume ratio of $1 / 3$. According to these results, $98 \%$ DBT removal was achieved in $3 \mathrm{~h}$ at a DES/model diesel volume ratio of $1 / 5$. Considering the efficiency and economy of the process, the volume ratio of CPLO 3:1 DES to oil was set to $1 / 5$ in further experiments.

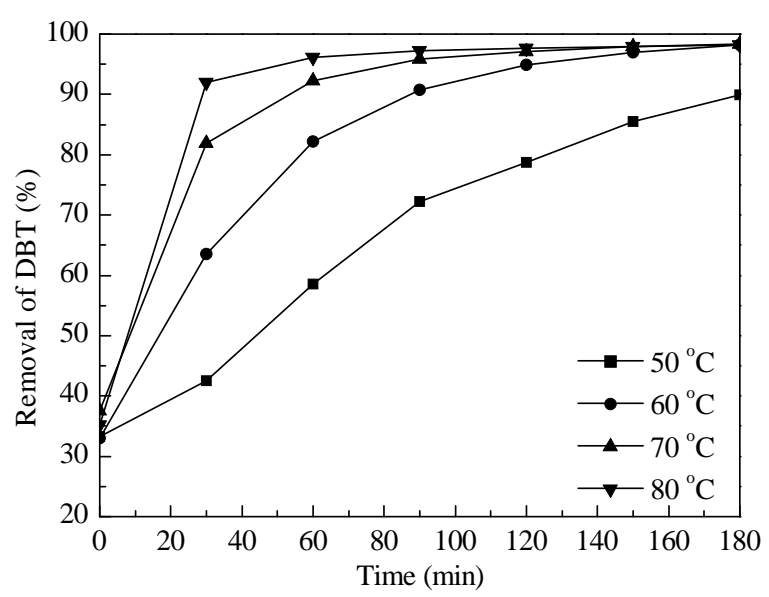

Fig. 5. DBT removal versus reaction time at different temperatures (50, 60,70 , and $80^{\circ} \mathrm{C}$ ). Reaction conditions: $V_{\text {DES }} / V_{\text {model diesel }}=1 / 5,0 / \mathrm{S}=5$ (molar ratio), DBT (S: $500 \mu \mathrm{g} \mathrm{g}^{-1}$ ) in $n$-octane.

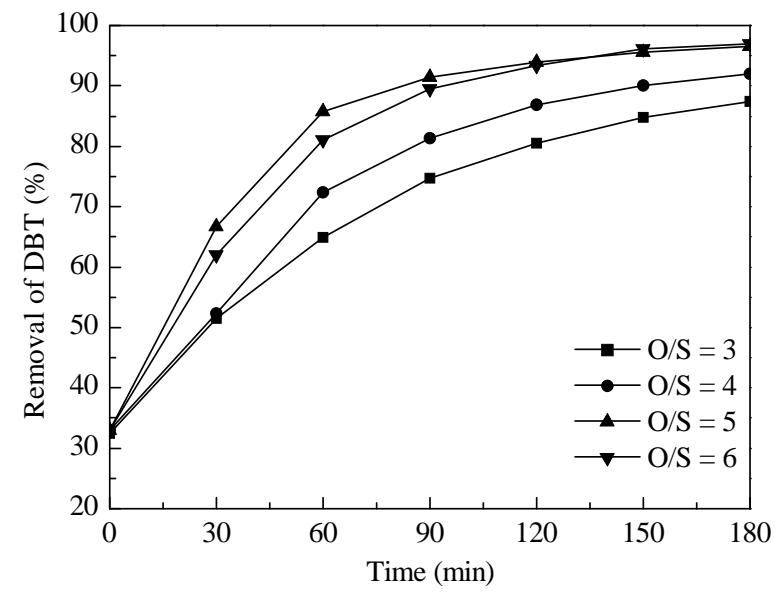

Fig. 6. DBT removal versus reaction time at different oxidant dosages $(\mathrm{O} / \mathrm{S}=3,4,5,6)$. Reaction conditions: $V_{\mathrm{DES}} / V_{\text {model diesel }}=1 / 5, T=60^{\circ} \mathrm{C}$, DBT (S: $500 \mu \mathrm{g} \mathrm{g}^{-1}$ ) in $n$-octane.

\subsection{Effect of different sulfur compounds on DBT removal}

Encouraged by the excellent capability of caprolactam-based acidic DESs for ODS, the oxidation of other sulfur compounds was performed at $60^{\circ} \mathrm{C}$ under the same conditions. The sulfur compound removal versus reaction time is shown in Fig. 8. The reactivity of different sulfur compounds followed the order: DBT > 4,6-DMDBT > BT. As we all know, two key factors influence significantly the reactivity of different sulfur compounds: the electron density on the sulfur atom and steric effects on the sulfur compounds [49]. The lower electron density on the sulfur atom of BT (5.696) results in its lower reactivity [50]. The difference in electron density between DBT and 4,6-DMDBT (5.760 and 5.758 for 4,6-DMDBT and DBT, respectively) is so small that it can be neglected $[50,51]$. As a result, the reactivity of DBT and 4,6-DMDBT is mostly influenced by steric effects induced by the methyl groups, which hamper the reaction of the sulfur atom with the peroxide species in the caprolactam-based acidic DESs.

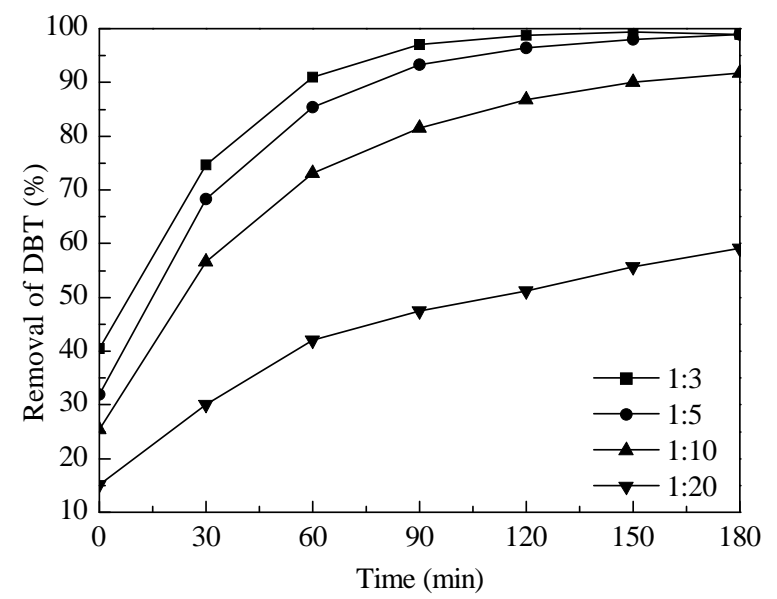

Fig. 7. DBT removal versus reaction time at different volume ratios of DES $/$ model diesel $\left(V_{\text {DES }} / V_{\text {model diesel }}=1 / 3,1 / 5,1 / 10,1 / 20\right)$. Reaction conditions: $T=60^{\circ} \mathrm{C}, \mathrm{O} / \mathrm{S}=5$, DBT (S: $500 \mu \mathrm{g} \mathrm{g}^{-1}$ ) in $n$-octane. 


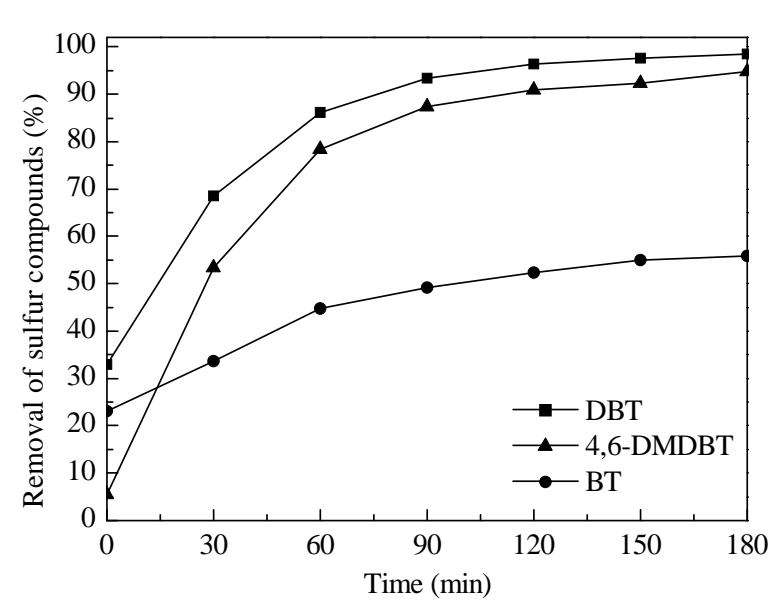

Fig. 8. Removal of different sulfur compounds versus reaction time. Reaction conditions: $T=60{ }^{\circ} \mathrm{C}, V_{\mathrm{DES}} / V_{\text {model diesel }}=1 / 5,0 / \mathrm{S}=5$, sulfur compounds (S: $500 \mu \mathrm{g} \mathrm{g}^{-1}$ ) in $n$-octane.

\subsection{Desulfurization mechanism in this catalytic system}

In light of our previous work and the aforementioned experimental results, a possible desulfurization mechanism for the present caprolactam-based acidic DESs would involve a dual activation concept [35]. First, the sulfur compounds are extracted into the DES where they interact, resulting in a distorted structure of the sulfur compound that is thus more prone to oxidation. Meanwhile, the carboxylic acid moieties in the DES are oxidized by $\mathrm{H}_{2} \mathrm{O}_{2}$ to the corresponding peracids $[50,52]$. Then, the peracids are able to oxidize the distorted sulfur compounds to the corresponding sulfones. The reduced peracids are then re-oxidized by $\mathrm{H}_{2} \mathrm{O}_{2}$ to start a new ODS cycle. That is, the DBT aromaticity is weakened upon interaction with the DES, concomitantly with the oxidation of the sulfur species by the peracids in the DES.

It is worth mentioning that the CPLO 3:1 DES desulfurization system shows the highest efficiency toward sulfur compound removal. A series of characterization experiments were conducted to investigate the effect of the composition of caprolactam-based acidic DESs on the hydrogen bonding. On the basis of such characterizations, the DES with the maximum hydrogen-bonding strength was found to present the lowest $T_{\mathrm{g}}$ and the highest ODS ability, as demonstrated by the above experiments with the caprolactam-based acidic DESs screened in this work. The hydrogen bonding in DESs is related to the composition and thus, the ODS system can be optimized to achieve the highest efficiency by tuning the DES composition. It is clear that the hydrogen bonding not only determines the physical properties of these eutectic mixtures, but also some of their chemical properties (such as their desulfurization ability). Consequently, smart tailoring of DESs at the molecular level can be realized by adjusting the composition of the eutectic mixtures, which influences the hydrogen-bonding strength of the system, thus modulating the physicochemical properties of the DES.

\section{Conclusions}

In summary, a series of caprolactam-based acidic DESs were prepared at different CPL/OXA molar ratios and used for the ODS of DBT and its derivatives under mild conditions. The desulfurization efficiency of the caprolactam-based acidic DESs reached as high as $98 \%$. The removal of different sulfur compounds followed the order: DBT > 4,6-DMDBT > BT. Additionally, an ODS mechanism has been proposed on the basis of a dual activation concept. The desulfurization efficiency of the system is related to the hydrogen-bonding strength. The stronger the hydrogen bonding, the greater the driving force for the ODS reaction. The hydrogen-bonding strength in these eutectic mixtures is influenced by the composition, which in turn determines the physical performance and chemical properties of the eutectic mixtures. This study is likely to stimulate the exploration of novel and green oxidative desulfurization processes with DESs.

\section{Acknowledgments}

We are grateful for the funding supported by National Natural Science Foundation of China (21676230, 21373177). This work also partly supported by Cooperation Project with SKLC (N-08-08). The authors are grateful to Professor Quan Shi, Shengmei $\mathrm{Lu}$ and Jun Li from Dalian Institute of Chemical Physics (DICP) for their help in DSC and ${ }^{1} \mathrm{H}$ NMR characterization.

\section{References}

[1] R. T. Yang, A. J. Hernandez-Maldonado, F. H. Yang, Science, 2003, 301, 79-81.

[2] Z. W. Sun, S. W. Wang, Q. L. Zhou, S. E. Hui, Appl. Energy, 2010, 87, 1505-1512.

[3] X. Gao, H. L. Ding, Z. Du, Z. L. Wu, M. X. Fang, Z. Y. Luo, K. F. Cen, Appl. Energy, 2010, 87, 2647-2651.

[4] C. Li, Z. X. Jiang, J. B. Gao, Y. X. Yang, S. J. Wang, F. P. Tian, F. X. Sun, X. P. Sun, P. L. Ying, C. R. Han, Chem. Eur. J., 2004, 10, 2277-2280.

[5] Z. X. Jiang, H. Y. Lü, Y. N. Zhang, C. Li, Chin. J. Catal., 2011, 32, 707-715.

[6] Y. S. Tian, G. H. Wang, J. Long, J. W. Cui, W. Jin, D. L. Zeng, Chin. J. Catal., 2016, 37, 2098-2105.

[7] C. M. Granadeiro, S. O. Ribeiro, M. Karmaoui, R. Valença, J. C. Ribeiro, B. de Castro, L. Cunha-Silva, S. S. Balula, Chem. Commun., 2015, 51, 13818-13821.

[8] S. N. Wei, H. J. He, Y. Cheng, C. P. Yang, G. M. Zeng, L. Kang, H. Qian, C. Y. Zhu, Fuel, 2017, 200, 11-21.

[9] K. Chen, N. Liu, M. H. Zhang, D. H. Wang, App. Catal. B, 2017, 212, 32-40.

[10] H. W. Yang, B. Jiang, Y. L. Sun, L. H. Zhang, Z. N. Huang, Z. Sun, N. Yang, J. Hazard. Mater., 2017, 333, 63-72.

[11] X. Y. Zeng, X. Y. Xiao, Y. Li, J. Y. Chen, H. L. Wang, App. Catal. B, 2017, 209, 98-109.

[12] H. W. Yang, B. Jiang, Y. L. Sun, L. H. Zhang, Z. N. Sun, J. Y. Wang, X. W. Tantai, Chem. Eng. J., 2017, 317, 32-41.

[13] H. Azimzadeh, A. Akbari, M. R. Omidkhah, Chem. Eng. J., 2017, 320, 189-200.

[14] X. Xiao, H. Zhong, C. Zheng, M. Lu, X. Zuo, J. Nan, Chem. Eng. J., 2016, 304, 908-916.

[15] S. H. Xun, W. S. Zhu, Y. H. Chang, H. P. Li, M. Zhang, W. Jiang, D. 


\section{Graphical Abstract}

Chin. J. Catal., 2018, 39: 1552-1559 doi: 10.1016/S1872-2067(18)63091-8

Oxidative desulfurization of diesel fuel with caprolactam-based acidic deep eutectic solvents: Tailoring the reactivity of DESs by adjusting the composition

Lingwan Hao, Ting Su, Dongmei Hao, Changliang Deng, Wanzhong Ren, Hongying Lü *

Yantai University

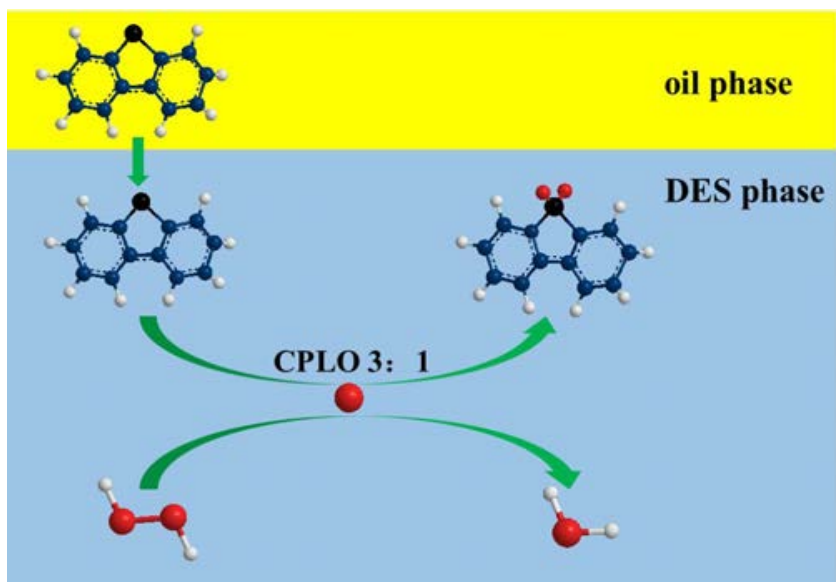

Sulfur compounds are extracted into the DES phase, where they interact. The carboxylic acid moieties of the DES are oxidized by $\mathrm{H}_{2} \mathrm{O}_{2}$ to the corresponding peracids, which in turn oxidize the sulfur compounds to the corresponding sulfones.

Zheng, Y. J. Qin, H. M. Li, Chem. Eng. J., 2016, 288, 608-617.

[16] W. H. Lo, H. Y. Yang, G. T. Wei, Green Chem., 2003, 5, 639-642.

[17] W. S. Zhu, H. M. Li, X. Jiang, Y. S. Yan, J. D. Lu, L. M. He, J. X. Xia, Green Chem., 2008, 10, 641-646.

[18] F. T. Li, C. G. Kou, Z. M. Sun, Y. J. Hao, R. H. Liu, D. S. Zhao, J. Hazard. Mater., 2012, 205, 164-170.

[19] H. Y. Lü, S. N. Wang, C. L. Deng, W. Z. Ren, B. C. Guo, J. Hazard. Mater., 2014, 279, 220-225.

[20] L. H. Zhang, J. Y. Wang, Y. L. Sun, B. Jiang, H. W. Yang, Chem. Eng. J., 2017, 328, 445-453.

[21] H. W. Yang, B. Jiang, Y. L. Sun, L. Hao, Z. H. Huang, L. H. Zhang, Chem. Eng. J., 2016, 306, 131-138.

[22] K. M. Docherty, C. F. Kulpa, Green Chem., 2005, 7, 185-189.

[23] T. P. Pham, C. W. Cho, Y. S. Yun, Water Res., 2010, 44, 352-372.

[24] M. Deetlefs, K. R. Seddon, Green Chem., 2010, 12, 17-30.

[25] A. P. Abbott, G. Capper, D. L. Davies, R. K. Rasheed, V. Tambyrajah, Chem. Commun., 2003, 70-71.

[26] E. L. Smith, A. P. Abbott, K. S. Ryder, Chem. Rev., 2014, 114, 11060-11082.

[27] M. Francisco, A. van den Bruinhorst, M. C. Kroon, Angew. Chem. Int. Ed., 2013, 52, 3074-3085.

[28] A. P. Abbott, D. Boothby, G. Capper, D. L. Davies, R. K. Rasheed, J. Am. Chem. Soc., 2004, 126, 9142-9147.

[29] H. G. Liao, Y. X. Jiang, Z. Y. Zhou, S. P. Chen, S. G. Sun, Angew. Chem. Int. Ed., 2008, 120, 9240-9243.

[30] E. R. Cooper, C. D. Andrews, P. S. Wheatley, P. B. Webb, P. Wormald, R. E. Morris, Nature, 2004, 430, 1012-1016.

[31] J. M. Yin, J. P. Wang, Z. Li, D. Li, G. Yang, Y. N. Cui, A. L. Wang, C. P. Li, Green Chem., 2015, 17, 4552-4559.

[32] W. S. Zhu, C. P. Wang, H. P. Li, P. W. Wu, S. H. Xun, W. Jiang, Z. G. Chen, Z. Zhao, H. M. Li, Green Chem., 2015, 17, 2464-2472.

[33] W. Liu, W. Jiang, W. Q. Zhu, W. S. Zhu, H. P. Li, T. Guo, W. H. Zhu, H.
M. Li, J. Mol. Catal. A, 2016, 424, 261-268.

[34] C. F. Mao, R. X. Zhao, X. P. Li, RSC Adv., 2017, 7, 42590-42596.

[35] H. Y. Lü, P. C. Li, C. L. Deng, W. Z. Ren, S. N. Wang, P. Liu, H. Zhang, Chem. Commun., 2015, 51, 10703-10706.

[36] X. D. Tang, Y. F. Zhang, J. J. Li, Y. Q. Zhu, D. X. Qing, Y. X. Deng, Ind. Eng. Chem. Res., 2015, 54, 4625-4632.

[37] L. W. Hao, M. R. Wang, W. J. Shan, C. L. Deng, W. Z. Ren, Z. Z. Shi, H. Y. Lü, J. Hazard. Mater., 2017, 339, 216-222.

[38] B. Jiang, H. W. Yang, L. H. Zhang, R. Y. Zhang, Y. L. Sun, Y. Huang, Chem. Eng. J., 2016, 283, 89-96.

[39] P. Gilli, L. Pretto, V. Bertolasi and G. Gilli, Acc. Chem. Res., 2009, 42, 33-44.

[40] X. L. Ma, S. Velu, J. H. Kim, C. S. Song, Appl. Catal. B, 2005, 56, 137-147.

[41] E. Gómez, N. Calvar, Á. Domínguez, Thermal Behaviour of Pure Ionic Liquids, 2015, 200-228.

[42] Y. H. Yu, X. M. Lu, Q. Zhou, K. Dong, H. W. Yao, S. J. Zhang, Chem. Eur. J., 2008, 14, 11174-11182.

[43] G. H. Tao, L. He, N. Sun, Y. Kou, Chem. Commun., 2005, 36, 3562-3564.

[44] C. L. Yin, A. T. Quitain, S. Yusup, M. Sasaki, Y. Uemura, T. Kida, Bioresource Technol., 2016, 199, 258-264.

[45] B. Y. Zhang, Z. X. Jiang, J. Li, Y. N. Zhang, F. Lin, Y. Liu, C. Li, J. Catal., 2012, 287, 5-12.

[46] B. M. Su, S. Zhang, Z. C. Zhang, J. Phys. Chem. B, 2004, 108, 19510-19517.

[47] M. S. Liu, X. Li, X. L. Lin, L. Liang, X. X. Gao, J. M. Sun, J. Mol. Catal. A, 2016, 412, 20-26.

[48] H. Y. Ji, J. Sun, P. W. Wu, B. L. Dai, Y. H. Chao, M. Zhang, W. Jiang, W. S. Zhu, H. M. Li, J. Mol. Catal. A, 2016, 423, 207-215.

[49] F. M. Collins, A. R. Lucy, C. Sharp, J. Mol. Catal. A, 1997, 117, 397-403. 
[50] S. Otsuki, T. Nonaka, N. Takashima, W. H. Qian, A. Ishihara, T. Imai, T. Kabe, Energy Fuels, 2000, 14, 1232-1239.

[51] Y. Shiraishi, K. Tachibana, T. Hirai, I. Komasawa, Ind. Eng. Chem.
Res., 2002, 41, 4362-4375.

[52] J. M. Campos-Martin, M. C. Capel-Sanchez, P. Perez-Presas, J. L. G. Fierro, J. Chem. Technol. Biotechnol., 2010, 85, 879-890.

\title{
己内酰胺基酸性低共熔剂对柴油的氧化脱硫：低共熔剂组成与催化反应活性
}

\author{
郝凌婉, 苏 婷, 郝冬梅, 邓昌亮, 任万忠, 吕宏缨 ${ }^{*}$ \\ 烟台大学化学化工学院, 绿色化学研究中心, 山东烟台264005
}

\begin{abstract}
摘要: 汽车尾气中硫化物的排放所导致的酸雨和 PM2.5 等环境污染问题广受关注. 各个国家和地区也相继制定了严格的 标准来控制柴油中的含硫量. 加氢脱硫工艺成熟, 但是需要在高温高压下进行, 并且柴油中二苯并噻吩及其衍生物的位阻 效应使得加氢脱硫难以将其脱除. 氧化脱硫作为加氢脱硫的补充技术, 以其反应条件温和等优点成为脱硫研究的重要课 题. 作为离子液体类似物, 低共熔剂不仅具有离子液体的优点, 而且无毒、生物可降解、价格低廉, 且制备过程简单, 是一 种绿色溶剂. 低共熔剂作为萃取剂和催化剂用于柴油的氧化脱硫中, 展现出非常好的应用前景.

尽管在低共熔剂氧化脱硫体系中氢键发挥着重要的作用, 但是关于低共熔剂组成, 氢键强度与氧化脱硫反应活性三者 之间关系的探究相对缺乏. 本文以己内酰胺和草酸为原料, 调节二者配比制备了一系列己内酰胺基低共熔剂. 通过差示扫 描量热法、傅里叶变换红外光谱、核磁共振氢谱以及热重分析对制备的低共熔剂进行表征, 从而确定组成与氢键之间的 关系. 将制备的低共熔剂应用于氧化脱硫体系中, 发现氧化脱硫率随着低共熔剂组成的变化而规律变化. 此外, 系统地研 究了影响氧化脱硫效率的反应参数. 结果表明, 在优化的反应条件下, 已内酰胺基酸性低共熔剂的脱硫率可以达到 $98 \%$. 该反应体系下, 三种不同硫化物的脱除率按照以下顺序依次递减: 二苯并噻吩 > 4,6-二甲基二苯并噻吩 > 苯并噻吩. 实 验数据与表征结果表明, 在低共熔剂氧化脱硫体系中氢键相互作用影响脱硫效率, 而氢键相互作用则可以通过调节低共熔 剂的组成来改变. 该结果为了解柴油深度脱硫机理提供了新的思路.
\end{abstract}

关键词: 酸性低共熔剂; 柴油; 二苯并噻吩; 氢键; 氧化脱硫

收稿日期: 2018-03-16. 接受日期: 2018-04-24. 出版日期: 2018-09-05.

*通讯联系人. 电话/传真: (0535)6902063; 电子信箱: hylv@ytu.edu.cn, hylvytu@163.com

基金来源：国家自然科学基金 (21676230, 21373177).

本文的电子版全文由Elsevier出版社在ScienceDirect上出版(http://www.sciencedirect.com/science/journal/18722067). 